University of Nebraska - Lincoln

DigitalCommons@University of Nebraska - Lincoln

Pirimiphos-Methyl Degradation and Insect Population Growth in Aerated and Unaerated Com Stored in Southeast Georgia: Small Bin Tests

\author{
Frank H. Arthur \\ USDA-ARS, frank.arthur@ars.usda.gov \\ James E. Throne \\ USDA-ARS, Manhattan, KS, james.throne@ars.usda.gov
}

Follow this and additional works at: https://digitalcommons.unl.edu/usdaarsfacpub

Arthur, Frank H. and Throne, James E., "Pirimiphos-Methyl Degradation and Insect Population Growth in Aerated and Unaerated Com Stored in Southeast Georgia: Small Bin Tests" (1994). Publications from USDA-ARS / UNL Faculty. 2028.

https://digitalcommons.unl.edu/usdaarsfacpub/2028

This Article is brought to you for free and open access by the U.S. Department of Agriculture: Agricultural Research Service, Lincoln, Nebraska at DigitalCommons@University of Nebraska - Lincoln. It has been accepted for inclusion in Publications from USDA-ARS / UNL Faculty by an authorized administrator of DigitalCommons@University of Nebraska - Lincoln. 


\title{
Pirimiphos-Methyl Degradation and Insect Population Growth in Aerated and Unaerated Corn Stored in Southeast Georgia: Small Bin Tests
}

\author{
FRANK H. ARTHUR AND JAMES E. THRONE \\ Stored-Product Insects Research \& Development Laboratory, USDA-ARS, 3401 Edwin Street, \\ Savannah, GA 31405
}

\begin{abstract}
J. Econ. Entomol. 87(3): 810-816 (1994)
ABSTRACT Lots of $229 \mathrm{~kg}$ untreated seed corn and corn treated with $8 \mathrm{ppm}$ pirimiphosmethyl were stored in unaerated bins and bins modified with a fan blower to provide aeration. The corn was infested artificially with adults of the red flour beetle, Tribolium castaneum (Herbst); the maize weevil, Sitophilus zeamais Motschulsky; and eggs of the Indianmeal moth, Plodia interpunctella (Hübner), to determine the effects of aeration on insect control in southeastern Georgia. Total temperature units in unaerated and aerated treated corn during the storage period of 15 October through 4 August were 5,729 and 5,196 degree-days, and moisture content was significantly greater in unaerated than in aerated bins. Pirimiphos-methyl degraded more quickly in unaerated than in aerated bins. No live insects were recovered from either unaerated or aerated treated bins. Total temperature units in untreated unaerated and untreated aerated com were 5,745 and 5,391 degree-days. Percentage moisture content, percentage insect-damaged kemels, and number of beetles were greater in unaerated untreated than in aerated untreated bins. Indianmeal moth populations did not increase with time in untreated unaerated or untreated aerated bins. Aeration potentially can reduce insect pest population levels and subsequent damage in corn stored in southeastern Georgia.
\end{abstract}

KEY WORDS pirimiphos-methyl, degradation, corn

COOLING AND DRYING raw agricultural commodities by low-volume aeration can reduce temperature and moisture content and thus limit insect population growth and development. Aeration is a recommended management practice for wheat storages in temperate climates such as northern Europe (Armitage \& Llewellin 1987, Lasseran \& Fleurat-Lessard 1990), Canada (Metzger \& Muir 1983), and the north-central United States (Gardner et al. 1988). Cuperus et al. (1986, 1990) reported that aeration limited insect infestations in wheat stored commercially and on farms in Oklahoma where early fall climate is favorable for insect population growth.

Two organophosphate insecticides are used as protectants in pest management programs for stored commodities. Chlorpyrifos-methyl is labeled for barley, oats, rice, sorghum, and wheat. Pirimiphos-methyl is labeled for corn and sorghum only. Organophosphate insecticides usually degrade rapidly when commodity temperature and moisture content increase (Desmarchelier \& Bengston 1979, Arthur et al. 1991, 1992). Therefore, cooling by aeration should reduce

This article reports the results of research only. Mention of a proprietary product does not constitute an endorsement or a recommendation for its use by USDA. degradation of organophosphate insecticides. However, Thomas (1990) conducted a study with chlorpyrifos-methyl on wheat stored in England and found no difference in rates of degradation in aerated and unaerated wheat. Those aeration systems operated continually throughout the spring and early summer instead of the normal operation at selected times during fall and winter cooling.

Currently, aeration is not considered an important component of management programs for stored raw commodities in the southeastern United States. Soft red winter wheat harvested during May and June usually is transported to processing plants shortly after drying and seldom is stored on farms. Corn is harvested in the fall and can be stored on farms for seed or animal feed or in commercial storages for food use. In past years, corn was treated with liquid malathion, but this insecticide has been removed from the post-harvest market; pirimiphos-methyl is the only labeled alternative protectant. There are no published reports concerning the effectiveness of aeration on corn stored in the southeastern United States. Therefore, our two objectives were to determine ( 1 ) if aeration during the fall and winter can limit insect infestations and 
(2) the effect of aeration on pirimiphos-methyl degradation.

\section{Materials and Methods}

'Pioneer 3320' seed corn from the 1991 crop was purchased from a local granary and fumigated with phosphine to eliminate any hidden insect infestation. Metal storage bins used in the test were conical in shape, $\approx 1.2 \mathrm{~m}$ in height and $0.61 \mathrm{~m}$ in diameter, and narrowed to a $10-\mathrm{cm}$ opening at the bottom. Each bin was mounted on a stand made of angle iron so that the tops of the bins were about $2.1 \mathrm{~m}$ from the ground. A $0.49-\mathrm{mm}$ diameter piece of 11 -gauge expanded metal with openings of 1.90 by $3.81 \mathrm{~cm}$ covered with $0.79-\mathrm{cm}$ plastic screening was wedged into the cone of each bin to make a false bottom. A Dayton Model 4C440 1/125 blower (Grainger, Jacksonville, FL) mounted over a hole cut into the plate that covered the bottom opening was installed in six bins (hereafter called aerated bins). The bottoms of six additional bins were covered with metal plates (hereafter called unaerated bins). After each of three unaerated and three aerated bins were filled on 9 October with $229.1 \mathrm{~kg}$ ( 9 bushels) of corn, the bins were picked up with a forklift and moved next to the back wall of an outside shed with an open front. Bins were arranged alternately, one unaerated, one aerated, and spaced about $0.31 \mathrm{~m}$ apart so that the third aerated bin was $\approx 0.62 \mathrm{~m}$ from the side wall of the shed.

On 11 October, another group of six bins (three aerated, three unaerated) were filled with corn treated with pirimiphos-methyl applied as follows: individual replicates were treated at the rate of $170 \mathrm{ml}$ formulated spray per $229 \mathrm{~kg}$, which is proportional to the field spray rate of $18,920 \mathrm{ml}$ per $25,454.54 \mathrm{~kg}$; solutions were formulated from a $600 \mathrm{mg}(\mathrm{AI}) / \mathrm{ml}$ (5 lbs [AI]/gal) EC (WilburEllis, West Burlington, IA) to give a theoretical deposition of $8 \mathrm{ppm}$; the insecticide was applied inside an enclosed warehouse, using a delivery system equipped with a Teejet nozzle number 650033 (Spraying Systems, Wheaton, IL) to spray the corn as it fell from a conveyor into a hopperbottom cart. Each replicate then was loaded into a bin, and these six bins were arranged alternately, $\approx 1 \mathrm{~m}$ in front of the six bins containing untreated corn.

After the bins were put in place, a grain probe was used to remove a $250 \mathrm{~g}$ sample from each bin, and moisture content was determined using a Burrows DMC 700 moisture computer (Seedburo, Chicago, IL). A second $250-\mathrm{g}$ sample was removed from each bin to determine initial pirimiphos-methyl residue. One temperature probe then was installed in each bin at a depth of $5.0 \mathrm{~cm}$ and connected to a data recorder (Omnidata, Logan, UT). An ambient temperature probe also was hung on the third untreated aerated bin, about $1 \mathrm{~m}$ from the ground. On 15 October, the data recorder was set to scan every $5 \mathrm{~s}$ and record temperature hourly. Each bin then was infested with 100 red flour beetle adults, Tribolium castaneum (Herbst); 100 maize weevil adults, Sitophilus zeamais Motschulsky; and 100 Indianmeal moth eggs, Plodia interpunctella (Hübner), all obtained from pesticide-susceptible strains maintained at the laboratory. Bins were covered with $0.709-\mathrm{cm}$ mesh plastic screening and No. 22 gauge wire screen anchored with pine two-byfours in an attempt to keep rodents out of the bins. A hand-held anemometer was used to estimate the airflow rates as $0.015 \mathrm{~m}^{3} / \mathrm{m} / 25.45 \mathrm{~kg}$ corn (0.5611 CFM per bushel).

All blowers were connected to a thermostat and an electric outlet, and the corn was cooled by adjusting the thermostat manually in accordance with the bin temperature and the temperatures in the aerated bins. When the ambient temperature was expected to drop due to an advancing cold front, the thermostat was set so the blowers would be activated when ambient temperature dropped below bin temperatures. The intention was continually to lower the thermostat temperature during the winter.

On 12 November (day 21), a grain probe was used to remove $250 \mathrm{~g}$ corn from the west side of the bin, $\approx 10 \mathrm{~cm}$ from the side, and a $250 \mathrm{~g} \mathrm{sam}$ ple from the center. Each sample was put in separate 0.47 -liter jars and frozen at $-17.8^{\circ} \mathrm{C}$ until analyzed for pirimiphos-methyl residue. Generalized analysis procedures for organophosphorous insecticides are described by Arthur et al. (1990, 1992). The bins were sampled on 2 December (day 48), 7 February (day 111), 6 April (day 170), 5 June (day 230), and 4 August (day 292). One week before these dates, a plastic pitfall trap (WB Probe II, Trece, Salinas, CA) was placed in the center of each bin at an approximate depth of $15.2 \mathrm{~cm}$. Rolled cardboard pupation traps for Indianmeal moths also were placed just under the corn surface in the north, east, south, and west positions. After 1 wk, the traps were removed, and all live insects were tabulated. A grain trier was used to remove $500 \mathrm{~g}$ corn from the west side of the bin, $\approx 10 \mathrm{~cm}$ from the side, and a 500-g sample from the center. Half of each sample $(250 \mathrm{~g})$ was put in separate 0.47-liter jars and frozen at $-17.8^{\circ} \mathrm{C}$ until analyzed for pirimiphos-methyl residue. The other half of each sample was placed in two new 0.47-liter jars. Samples were shaken separately over a U.S. standard No. 8 sieve ( $2.38 \mathrm{~mm}$ openings) to remove live insects, and the amount of dockage (ground flour, foreign material, ground grains, and insect frass) was weighed for each sample. Moisture content was determined, the corn was poured back into the jar, and a cylinder ( 15.8 by $3.2 \mathrm{~cm}$ ) attached to a jar lid was used to remove a $68-\mathrm{ml}$ subsample, from which 100 kernels were examined for insect damage. When sampling was 
completed, all live insects were returned to the bins, and the bins were reinfested with the numbers and species described earlier.

Numbers for each insect species collected in the pitfall traps, cardboard traps, and grain samples $(229 \mathrm{~kg}$ corn) for each sample date were analyzed separately. Differences between aeration regimes in beetle counts by trapping method, percentage moisture contents, percentage damaged kernels, dockage weight, and pirimiphos-methyl residues were analyzed using repeated measures analysis of variance (General Linear Models Procedure, SAS Institute 1987). Beetle counts were transformed as log (count + 0.1 ), percentage damaged kernels were transformed as (percent +0.5$)^{0.5}$, and dockage weight was transformed as $\log$ (weight +0.01 ) before analysis to stabilize variances.

Degradation of pirimiphos-methyl was estimated using the method of Desmarchelier \& Bengston (1979):

$$
\operatorname{PPM}(t+1)=\operatorname{PPM}(t) * e^{-k t}
$$

where $\mathrm{ppm}=$ parts per million pirimiphosmethyl, $t=$ time, and $k$ is an empirical rate constant defined as

$$
k=\frac{\left|\log _{e}(0.5)\right|}{10^{\log _{10}(19)-\log _{10}(r h / 50)-\left(0.04^{*}(t e m p-30)\right)}}
$$

where $r h=$ relative humidity and temp $=$ temperature $\left({ }^{\circ} \mathrm{C}\right)$. Estimated pirimiphos-methyl residues were compared with observed residue levels to determine the validity of the equation over a wide range of environmental conditions. After validation, the equation was used to determine the amount of change in temperature or moisture content of grain that would have been required in unaerated bins treated with a calculated dosage of $8.0 \mathrm{ppm}$ pirimiphos-methyl to result in certain levels of pirimiphos-methyl residues at the end of the storage period. Because moisture content was measured bimonthly, we interpolated between measured moisture contents to obtain estimates of daily moisture content.

\section{Results}

Ambient Temperature. From 15 Oct (month 0) to $21 \mathrm{Dec}(\approx 60 \mathrm{~d})$, daily ambient temperatures ranged from highs exceeding $20^{\circ} \mathrm{C}$ to lows of $\approx 6^{\circ} \mathrm{C}$ (Fig. 1A). During the winter months of December to March (day 60-120), there were

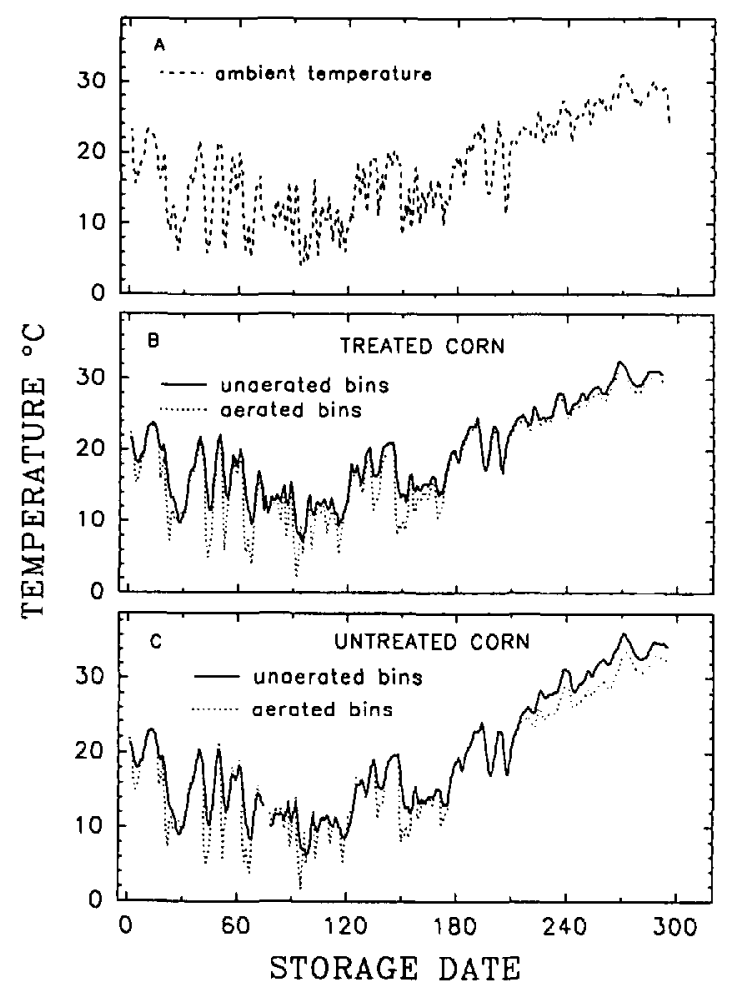

Fig. 1. Daily ambient air temperature from $15 \mathrm{Oc}-$ tober 1991 to 4 August 1992 (1A), Average daily temperature of $229-\mathrm{kg}$ unaerated and aerated corn treated at a calculated rate of $8 \mathrm{ppm}$ pirimiphos-methyl and stored from 15 October to 4 August in small bins (B), Average daily temperature of $229-\mathrm{kg}$ untreated unaerated and untreated aerated corn stored from 15 October to 4 August in small bins ( $1 C$ ).

several sharp drops in temperature after warm periods. A general warming trend began after $180 \mathrm{~d}$ and by $210 \mathrm{~d}$, temperature fluctuations were less severe, and the range between the high and low temperatures usually did not exceed $6^{\circ} \mathrm{C}$.

Treated Corn. Average daily temperatures in unaerated corn dropped below $10^{\circ} \mathrm{C}$ on four occasions during the first $180 \mathrm{~d}$ of the test (Fig. 1B). In contrast, temperatures in aerated bins were often below $10^{\circ} \mathrm{C}$ and were usually near the ambient temperatures for that particular time. Plotted temperatures for unaerated and aerated bins show the cooling effects of the aeration system. Summing the daily unaerated and aerated temperatures yields totals of 5,729 and $5,196{ }^{\circ} \mathrm{C}$-d, respectively.

Table 1. Mean \pm SEM pirimiphos-methyl residue (ppm) on unaerated and aerated corn sampled at selected intervals during storage

\begin{tabular}{ccccccc}
\hline \hline \multirow{2}{*}{ Bins } & \multicolumn{6}{c}{ Days after storage } \\
\cline { 2 - 7 } & 21 & 48 & 111 & 170 & 230 & 292 \\
\hline Unaerated & $7.3 \pm 0.67$ & $6.2 \pm 0.10$ & $5.4 \pm 0.21$ & $4.9 \pm 0.34$ & $3.2 \pm 0.23$ & $2.5 \pm 0.19$ \\
Aerated & $6.5 \pm 0.24$ & $5.4 \pm 0.39$ & $4.9 \pm 0.35$ & $5.6 \pm 0.40$ & $3.8 \pm 0.19$ & $3.4 \pm 0.27$ \\
\hline
\end{tabular}



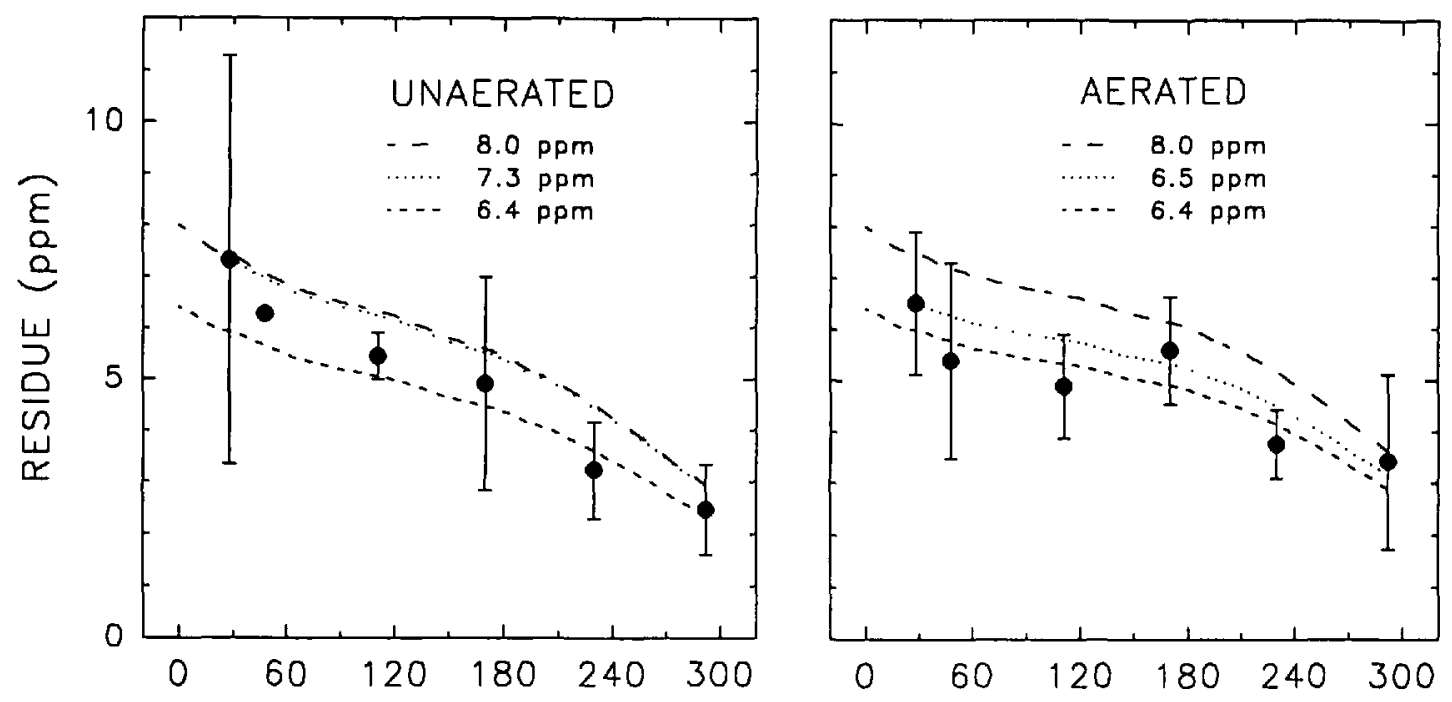

\section{STORAGE DATE}

Fig. 2. Pirimiphos-methyl degradation in aerated and unaerated bins containing $229 \mathrm{~kg}$ corn. Observed (closed circles); estimated (Desmarchelier and Bengston 1979) from initial dosage of 8 ppm (long dashes); estimated from measured residue at month 0.7 (dots); and estimated from $20 \%$ loss from calculated dosage at month 0 (short dashes). Measured temperatures and moisture contents were used to derive estimations.

After $21 \mathrm{~d}$ of storage, pirimiphos-methyl residues in unaerated and aerated corn were $7.31 \pm$ 0.68 and $6.51 \pm 0.24 \mathrm{ppm}$, respectively. Residues gradually declined during the test (Table 1). Repeated-measures analysis of variance indicated that pirimiphos-methyl residues did not differ significantly with aeration regime $[F=$ $0.00 ; \mathrm{df}=1,4 ; P=0.98]$, but aeration regime by time interaction was significant $[F=3.22 ; \mathrm{df}=5$, $20 ; P=0.03]$. This indicates the interaction term was significant and that residue levels varied with aeration regime.

Estimated results derived from using the Desmarchelier and Bengston equation agreed with observed pirimiphos-methyl residues when initiated with $8 \mathrm{ppm}$ minus $20 \%$ initial residue loss (Fig. 2) (Thomas 1987; Arthur et al. 1991, 1992) or when initiated with the observed 21-d values. The equation gives accurate predictions over a broad range of temperatures $\left(2.1^{\circ}-32.5^{\circ} \mathrm{C}\right)$ and relative humidities $(53.6-77.8 \%)$ and shows that aeration would have had to have reduced measured temperatures by $3.5^{\circ} \mathrm{C}$ on each day $(1,022$ degree-days during the storage period) or reduced measured moisture content by $3 \%$ on each day to reduce pesticide degradation by $1 \mathrm{ppm}$ during the 292-d storage period in our study (Table 2). In our bins, a 0.9 -ppm reduction in pesticide degradation was achieved during the 292-d storage period in aerated bins by lowering the total degree-days by 533 and by lowering the moisture content of the corn.
Corn moisture content in unaerated and aerated corn generally declined during the test and was greater in unaerated corn on all sample dates (Table 3). No live insects were ever detected in pitfall traps, cardboard traps, or corn samples from corn treated with pirimiphos-methyl. There

Table 2. Estimated pirimiphos-methyl residue levels at the end of the 292-d storage period when temperatures and moisture contents are reduced by varying amounts by aeration

\begin{tabular}{cc}
\hline \hline Reductions & \multicolumn{2}{c}{ Estimated final residue, ppm } \\
\hline Temperature, ${ }^{\circ} \mathrm{C}$ & \\
0 & 2.94 \\
1 & 3.23 \\
2 & 3.52 \\
3 & 3.80 \\
4 & 4.07 \\
5 & 4.34 \\
6 & 4.83 \\
7 & 5.06 \\
8 & 5.28 \\
Moisture contents, \% & \\
0 & 2.94 \\
1 & 3.30 \\
2 & 3.69 \\
3 & 4.13 \\
4 & 5.18 \\
\hline
\end{tabular}

Predicted pirimiphos-methyl residue after $292 \mathrm{~d}$, based on an initial deposit of $8.0 \mathrm{ppm}$ and using actual or simulated temperature and moisture content of unaerated corn (estimates using model of Desmarchelier \& Bengston 1979). 
Table 3. Mean percentage moisture content $( \pm S E M)$ of unaerated and aerated corn treated at a calculated rate of 8 ppm pirimiphos-methyl and sampled at selected intervals during storage

\begin{tabular}{cccccc}
\hline \hline \multirow{2}{*}{ Bins } & \multicolumn{5}{c}{ Days after storage } \\
\cline { 2 - 6 } & 48 & 111 & 170 & 230 & 292 \\
\hline Unaerated & $15.4 \pm 0.13$ & $14.8 \pm 0.10$ & $14.7 \pm 0.20$ & $14.4 \pm 0.15$ & $14.0 \pm 0.14$ \\
Aerated & $14.4 \pm 0.16$ & $13.0 \pm 0.05$ & $12.6 \pm 0.06$ & $13.2 \pm 0.09$ & $13.2 \pm 0.04$ \\
\hline
\end{tabular}

Moisture content was significantly greater in aerated than in unaerated corn as determined by repeated measures analysis of variance (aeration regime: $F=77.41, \mathrm{df}=1,4 ; P<0.001$; aeration by time interaction: $F=14.44, \mathrm{df}=4,16 ; P<0.001$ ).

Table 4. Mean ( $(S E M)$ number of red flour beetles collected in pitfall traps and cardboard traps left for 1 wk in bins containing $229 \mathrm{~kg}$ ungerated untreated corn and $229 \mathrm{~kg}$ aerated untreated corn

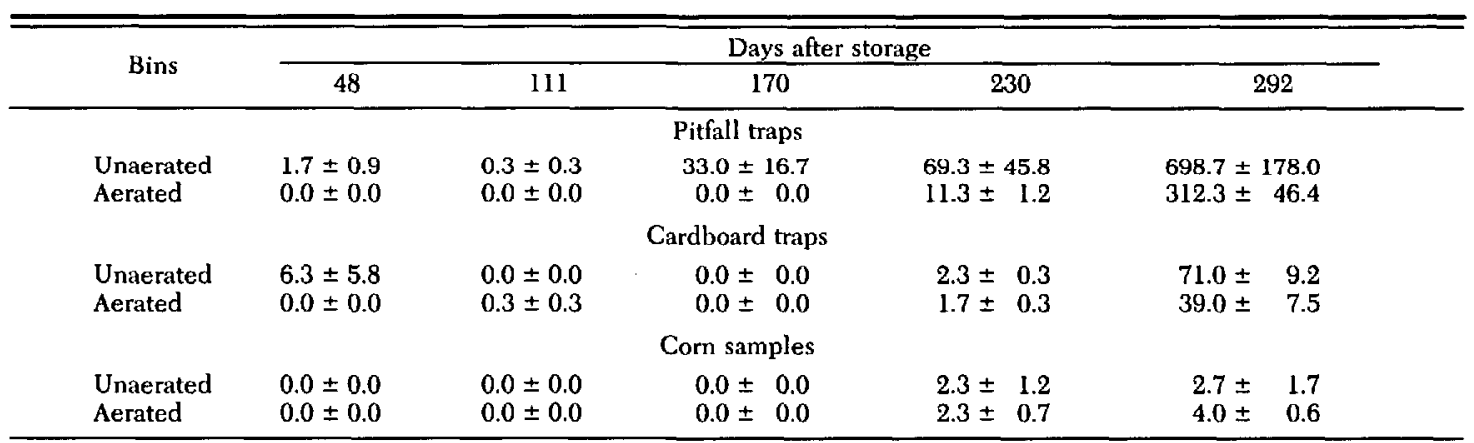

Mean $( \pm S E M)$ number of red flour beetles collected from $250 \mathrm{~g}$ corn samples taken after traps were removed from the bins.

Table 5. Mean ( $(S E M)$ number of maize weevils collected in pitfall traps and cardboard traps left for 2 wk in bins containing $229 \mathrm{~kg}$ unaerated untreated corn and $229 \mathrm{~kg}$ aerated untreated corn.

\begin{tabular}{|c|c|c|c|c|c|}
\hline \multirow{2}{*}{ Bins } & \multicolumn{5}{|c|}{ Days after storage } \\
\hline & 48 & 111 & 170 & 230 & 292 \\
\hline \multicolumn{6}{|c|}{ Pitfall traps } \\
\hline Unaerated & $0.3 \pm 0.3$ & $1.3 \pm 0.7$ & $15.3 \pm 4.5$ & $20.3 \pm 10.8$ & $0.0 \pm 0.0$ \\
\hline Aerated & $0.0 \pm 0.0$ & $0.0 \pm 0.0$ & $0.3 \pm 0.3$ & $2.7 \pm 0.3$ & $0.0 \pm 0.0$ \\
\hline \multicolumn{6}{|c|}{ Cardboard traps } \\
\hline Unaerated & $0.0 \pm 0.0$ & $0.0 \pm 0.0$ & $0.0 \pm 0.0$ & $1.3 \pm 1.3$ & $11.0 \pm 2.5$ \\
\hline Aerated & $0.0 \pm 0.0$ & $0.0 \pm 0.0$ & $0.0 \pm 0.0$ & $0.7 \pm 0.7$ & $8.3 \pm 2.7$ \\
\hline \multicolumn{6}{|c|}{ Com samples } \\
\hline Unaerated & $0.03 \pm 0.3$ & $0.3 \pm 0.3$ & $3.0 \pm 2.5$ & $5.7 \pm 3.7$ & $45.0 \pm 17.2$ \\
\hline Aerated & $0.0 \pm 0.0$ & $0.0 \pm 0.0$ & $1.7 \pm 1.2$ & $2.7 \pm 1.7$ & $28.3 \pm 15.1$ \\
\hline
\end{tabular}

Mean ( \pm SEM) number of maize weevils collected from $250 \mathrm{~g}$ corn samples taken after traps were removed from the bins.

Table 6. Mean ( \pm SEM) number of Indianmeal moths of all life stages collected in cardboard traps left for 1 wk in bins containing $229 \mathrm{~kg}$ unaerated untreated corn and $229 \mathrm{~kg}$ aerated untreated corn

\begin{tabular}{cccccc}
\hline \hline \multirow{2}{*}{ Bins } & \multicolumn{5}{c}{ Days after storage } \\
\cline { 2 - 6 } & 48 & 111 & 170 & 230 & 292 \\
\hline Unaerated & $0.0 \pm 0.0$ & $1.3 \pm 0.7$ & $0.0 \pm 0.0$ & $5.3 \pm 1.8$ & $0.0 \pm 0.0$ \\
Aerated & $0.0 \pm 0.0$ & $0.7 \pm 0.7$ & $0.0 \pm 0.0$ & $21.0 \pm 7.1$ & $1.7 \pm 1.2$ \\
\hline
\end{tabular}

All values for pitfall traps and corn samples were 0 except for $0.3 \pm 0.3$ in pitfall traps from unaerated bins at month 3.7 . 
Table 7. Mean ( \pm SEM) percentage moisture content insect-damaged kernels, and dockage weight of untreated corn sampled at selected intervals during storage

\begin{tabular}{|c|c|c|c|c|c|}
\hline \multirow{2}{*}{ Bins } & \multicolumn{5}{|c|}{ Days after storage } \\
\hline & 48 & 111 & 170 & 230 & 292 \\
\hline \multicolumn{6}{|c|}{ Moisture content ${ }^{a}$} \\
\hline $\begin{array}{l}\text { Unaerated } \\
\text { Aerated }\end{array}$ & $\begin{array}{l}15.2 \pm 0.13 \\
14.0 \pm 0.10\end{array}$ & $\begin{array}{l}14.7 \pm 0.18 \\
13.2 \pm 0.02\end{array}$ & $\begin{array}{l}14.5 \pm 0.19 \\
12.7 \pm 0.04\end{array}$ & $\begin{array}{l}14.4 \pm 0.21 \\
13.2 \pm 0.08\end{array}$ & $\begin{array}{l}13.5 \pm 0.20 \\
13.2 \pm 0.07\end{array}$ \\
\hline \multicolumn{6}{|c|}{ \% Damaged kernels" } \\
\hline $\begin{array}{l}\text { Unaerated } \\
\text { Aerated }\end{array}$ & $\begin{array}{l}0.5 \pm 0.22 \\
0.0 \pm 0.00\end{array}$ & $\begin{array}{l}0.2 \pm 0.17 \\
0.0 \pm 0.00\end{array}$ & $\begin{array}{l}0.7 \pm 0.21 \\
0.0 \pm 0.00\end{array}$ & $\begin{array}{l}3.0 \pm 1.03 \\
1.0 \pm 0.37\end{array}$ & $\begin{array}{r}14.3 \pm 0.12 \\
6.2 \pm 0.83\end{array}$ \\
\hline \multicolumn{6}{|c|}{ Dockage $^{c}$} \\
\hline $\begin{array}{l}\text { Unaerated } \\
\text { Aerated }\end{array}$ & $\begin{array}{l}0.1 \pm 0.10 \\
0.0 \pm 0.00\end{array}$ & $\begin{array}{l}0.1 \pm 0.01 \\
0.0 \pm 0.01\end{array}$ & $\begin{array}{l}0.1 \pm 0.01 \\
0.1 \pm 0.01\end{array}$ & $\begin{array}{l}0.2 \pm 0.03 \\
0.2 \pm 0.05\end{array}$ & $\begin{array}{l}0.5 \pm 0.06 \\
0.6 \pm 0.07\end{array}$ \\
\hline
\end{tabular}

\footnotetext{
"Moisture content was significantly greater in unaerated than in aerated corn as determined by repeated measures analysis of variance $[F=79.6 ; \mathrm{df}=1,4 ; P<0.001]$.

"Percentage of kernels damaged by insects was significantly greater in unaerated corn than in aerated corn as determined by repeated measures analysis of variance $[F=14.60 ; \mathrm{df}=1,4 ; P=0.02]$.

${ }^{r}$ Dockage weight did not vary with aeration regime [aeration regime: $F=0.50 ; \mathrm{df}=1,4 ; P=0.52$; aeration by time interaction: $F=0.77 ; \mathrm{df}=4,16 ; P=0.56]$.
}

were no insect-damaged kernels, and dockage weight in corn samples averaged 0.0 to $0.1 \mathrm{~g}$.

Untreated Corn. For the first $210 \mathrm{~d}$, daily temperatures in untreated corn were similar to temperatures in treated corn, regardless of aeration regime (Fig. 1C). After this time, temperatures in untreated corn began increasing, with a noticeable divergence between the unaerated and aerated corn. Daily temperatures were $\approx 2^{\circ} \mathrm{C}$ greater in unaerated corn. Temperature summation yielded total estimates of 5,745 and 5,391 degree-days for unaerated and aerated corn, respectively.

Most of the live red flour beetles collected from unaerated and aerated bins were caught in the pitfall traps (Table 4). More red flour beetles were collected in pitfall traps from unaerated bins than from aerated bins $(F=8.45 ; \mathrm{df}=1,4$; $P=0.04)$. Red flour beetles in cardboard traps and corn samples from unaerated bins versus aerated bins were not significantly different $(F=$ 3.93; $\mathrm{df}=1,4 ; P=0.12$ and $F=2.30 ; \mathrm{df}=1,4$; $P=0.10$, respectively). Treatment-by-time interaction was not significant for pitfall traps, cardboard traps, or corn samples $(F=1.65 ; \mathrm{df}=4,16$; $P=0.21, F=0.80 ; \mathrm{df}=4,16 ; P=0.42$, and $F=$ 0.45 ; $\mathrm{df}=4,16 ; P=0.77$, respectively).

Maize weevils were much less abundant than red flour beetles in unaerated and aerated bins (Table 5). At all sample points except day-292 maize weevils were more abundant in pitfall traps than in cardboard traps or corn samples; however, no live weevils were caught in pitfall traps at day 292. There was no significant difference in maize weevils collected from pitfall traps, cardboard traps, or corn samples for unaerated vs aerated bins $(F=4.05 ; \mathrm{df}=1,4 ; P=4.05$, $F=0.10 ; \mathrm{df}=1,4 ; P=0.77$, and $F=1.17 ; \mathrm{df}=$ 1,$4 ; P=0.34$, respectively). Treatment-by-time interaction was significant for pitfall traps $(F=$ $3.40 ; \mathrm{df}=4,16 ; P=0.03$ ) but not for cardboard traps or corn samples $(F=0.05 ; \mathrm{df}=4,16 ; P=$ 0.99 and $F=0.11 ; \mathrm{df}=1,4$; and $P=0.94$, respectively).

Indianmeal moth populations did not become established in unaerated or aerated corn (Table 6). All but one of the total collected during the study were found in the cardboard traps. The number of moths in unaerated versus aerated bins was not significantly different $(F=3.22$; $\mathrm{df}=1,4 ; P=0.15)$, and there was no treatment by time interaction $(F=1.79, \mathrm{df}=4,16 ; P=$ 0.18 ).

Moisture content generally declined during storage and was always greater in unaerated corn than in aerated corn (Table 7). Although there were few insect-damaged kernels until the final sample date, the percentage of insect-damaged kernels was always greater in unaerated corn than in aerated corn. Dockage weight did not vary with aeration regime (Table 7 ).

\section{Discussion}

Thomas (1990) aerated wheat in Great Britain continually throughout the spring and summer months and found no differences in chlorpyrifosmethyl degradation or biological efficacy of the insecticide, even though the aerated wheat was warmer than the unaerated wheat. However, that test was conducted to determine whether aeration would increase pesticide loss by removing vapors from the grain. Thus the study does not indicate whether cooling by aeration would slow pesticide degradation or insect population growth.

Insects were introduced into the corn every two months during storage in our test; yet, Indianmeal moths did not become established in unaerated bins or aerated bins, and beetle populations did not increase in unaerated bins until temperatures warmed in the spring. During much of the 
year, temperatures were near the lower developmental limits of $17^{\circ} \mathrm{C}$ for Indianmeal moths and $20^{\circ} \mathrm{C}$ for red flour beetles and maize weevils (Howe 1965). The red flour beetle preys on the immature stages of Indianmeal moths and externally feeding beetles (LeCato 1975, LeCato \& Flaherty 1973); therefore, predation may account for the low numbers of Indianmeal moths in our tests. Red flour beetle predation on maize weevil is unlikely because the maize weevil is an internal feeder and larvae develop inside the corn kernel, but the dense red flour beetle populations during the latter months could have produced an inhibitory effect on the maize weevil. Arthur et al. (1990) also found low maize weevil populations in corn heavily infested with red flour beetles.

Aeration further delayed insect population development in the small bins, even though the 229-kg mass had little insulating properties and ambient temperature changes were transferred to the corn. Although the small size of the bins may not be indicative of bulk temperatures in larger bins, they do provide an indication of temperature conditions in the upper surface of a corn mass inside a large bin. Temperatures on the corn surface and along the bin walls would probably fluctuate in response to ambient temperatures. These areas would be vulnerable to insect infestation during storage, because during warm periods temperatures on the surface and inside the bin walls would be warmer than the temperature of the insulated bulk mass. Frequent aeration may help reduce temperatures and inhibit insect growth and development in warm peripheral areas.

Aeration has potential for increased utilization in management programs for corn stored in warm regions of the southeastern United States. Previous studies show that corn stored in 76-bushel bulks remained below $22^{\circ} \mathrm{C}$ until mid-April (Arthur et al. 1990). Aeration would decrease temperatures during the passage of cold fronts which would likely hold temperatures at $15-20^{\circ} \mathrm{C}$ between October and May. These temperatures would be near the lower developmental thresholds for most stored-product insects (Howe 1965).

\section{Acknowledgments}

The authors thank G. W. Murray and J. E. O'Bryan for technical assistance. We also thank E. Z. Cooper, Jr. and R. A. Simonaitis for pirimiphos-methyl residue analyses. We also thank G. W. Cuperus and J. D. Sedlacek for reviewing the manuscript. Wilbur-Ellis Company, West Burlington, IA, provided the pirimiphosmethyl insecticide used in this study.

\section{References Cited}

Armitage, D. M. \& B. E. Llewellin. 1987. The survival of Oryzaephilus surinamensis (L.) (Co- leoptera: Silvanidae) and Sitophilus granarius (L.) (Coleoptera: Curculionidae) in aerated bins of wheat during British winters. Bull. Entomol. Res. 77: 457-466.

Arthur, F. H., J. E. Throne \& R. A. Simonaitis. 1991. Chlorpyrifos-methyl degradation and biological efficacy toward maize weevils (Coleoptera: Curculionidae) on corn stored at four temperatures and three moisture contents. J. Econ. Entomol. 84: 1926-1932.

Arthur, F. H., J. E. Throne \& R. A. Simonaitis. 1992. Degradation and biological efficacy of chlorpyrifosmethyl on wheat stored at five temperatures and three moisture contents. J. Econ. Entomol. 85: 1994-2002.

Arthur, F. H., J. E. Throne, R. A. Simonaitis \& J. M. Zehner. 1990. Evaluation of chlorpyrifos-methyl and chlorpyrifos-methyl plus methoprene as protectants of stored corn: small bin tests. J. Econ. Entomol. 83: 1114-1121.

Cuperus, G. W., C. K. Prickett, P. D. Bloome \& J. T. Pitts. 1986. Insect populations in aerated and unaerated stored wheat in Oklahoma. J. Kans. Entomol. Soc. 59: 620-627.

Cuperus, G. W., R. T. Noyes, W. S. Fargo, B. L. Clary, D. C. Arnold \& K. Anderson, 1990. Management practices in a high-risk stored-wheat system in Oklahoma. Am. Entomol. 36: 129-134.

Desmarchelier, J. M. \& M. Bengston. 1979. The residual behaviour of chemicals on stored grain, pp. 138-151. In Proceedings, Second International Working Conference on Stored-Product Entomology, Ibadan, Nigeria.

Gardner, R. D., P. K. Harein \& B. Subramanyam. 1988. Management of stored barley in Minnesota: practices versus recommendations. Am. Entomol. 34: 22-26.

Howe, R. W. 1965. A summary of estimates of opti$\mathrm{mal}$ and minimal conditions for population increase of some stored product insects. J. Stored Prod. Res. 1: $177-184$.

Lasseran, J. C. \& F. Fleurat-Lessard. 1990. Aeration of grain with ambient or artificially cooled air: a technique to control weevils in temperate climates. pp. 1221-1231. In Proceedings, Fifth International Working Conference on Stored-Product Protection, Bordeaux, France.

LeCato, G. L. 1975. Interactions among four species of stored-product insects in corn: a multifactorial study. Arn. Entomol. Soc. Am. 68: 677-679.

LeCato, G. L. \& B. R. Flaherty. 1973. Tribolium castaneum progeny production and development on diets supplemented with eggs or adults of Plodia interpunctella. J. Stored Prod. Res. 9: 199-203.

Metzger, J. F. \& W. E. Muir. 1983. Aeration of stored wheat in the Canadian Prairies. Can. Agric. Eng. 25: 127-137.

SAS Institute. 1987. SAS/STAT guide for personal computers, version 6 ed, SAS Institute, Cary, NC.

Thomas, K. P. 1990. The effects of low-volume aeration on the residues and biological effectiveness of chlorpyrifos-methyl applied to wheat. Pestic. Sci. 29: 135-142.

Thomas, K. P., D. B. Pininger \& D. R. Wilkin. 1987. An assessment of chlorpyrifos-methyl, etrimphos, fenitrothion, and pirimiphos-methyl as grain protectants. Pest. Sci. 21: 57-72.

Received for publication 2 August 1993; accepted 3 January 1993. 